\title{
Analysis Of Efficiency Of Rice Farming Production Factors In Village New Kecamatan Batang Kuis Deli Serdang District
}

\section{Analisis Efisiensi Faktor Produksi Usahatani Padi Di Desa Baru Kecamatan Batang Kuis Kabupaten Deli Serdang}

\author{
Henny wahyuni $^{1{ }^{* *}}$, Adriansyah ${ }^{2)}$, Lisdayani ${ }^{3)}$, Putri Mustika Sari ${ }^{4)}$ \\ ${ }^{1,2)}$ Dosen Fakultas Pertanian Program studi Agribisnis, Universitas Alwasliyah Medan \\ Jl. Sisingamangaraja Km 5.5 No.10 Medan. Telp/fax : 061-7851881 \\ ${ }^{3,4)}$ Dosen Fakultas Pertanian Program studi Agroteknologi, Universitas Alwasliyah Medan \\ Jl. Sisingamangaraja Km 5.5 No.10 Medan. Telp/fax : 061-7851881 \\ Email: Henny0471@gmail.com
}

\begin{abstract}
The government of North Sumatra is trying to increase the production and productivity of rice commodities. The level of income derived from rice farming is often lower when compared to planting horticultural products or other agricultural commodities. The level of income derived from rice farming is often lower when compared to planting horticultural products or other agricultural commodities. Basically, rice farming has two factors that will affect the production process, namely internal land use, labor and capital factors and external factors which include factors of production that cannot be controlled by farmers such as climate, weather, price changes and so on. North Sumatra Province began to develop organic agriculture, especially for rice plants to reduce farmers' dependence on chemical pesticides and fertilizers. The purpose of this study is to analyze the factors of production that affect rice farming, and to analyze the level of efficiency of the use of production factors in rice farming in the new village of quiz stem sub-district. The method used in the research in descriptive method is sampling and interviews with farmers in the new village of Kec. Batang quiz. The parameters observed include the analysis of production factors and the analysis of the efficiency of the use of production factors. The results obtained from the study that most farmers in the new village are high school graduates and all the factors of production have a very significant effect on rice farming in the new village. And the variable seed, chemical fertilizer, organic fertilizer, land area and labor very significantly affect production. In the future it is expected that rice farmers in the new village can minimize the use of seeds, chemical fertilizers and pesticides so that optimal rice production is obtained.
\end{abstract}

Keywords: Rice, farming, efficiency of production factors

\begin{abstract}
Abstrak.
Pemerintah Sumatera utara berusaha meningkatkan produksi dan produktifitas komoditi padi. Tingkat pendapatan yang diperoleh dari bertanam padi sering kali lebih rendah jika dibandingkan dengan bertanam produk hortikultura atau komoditi pertanian yang lainnya. Tingkat pendapatan yang diperoleh dari bertanam padi sering kali lebih rendah jika dibandingkan dengan bertanam produk hortikultura atau komoditi pertanian yang lainnya. Pada dasarnya usahatani padi memiliki dua faktor yang akan mempengaruhi proses produksi, yaitu faktor internal penggunaan lahan, tenaga kerja dan modal serta faktor-faktor eksternal yang meliputi faktor produksi yang tidak dapat dikontrol oleh petani seperti iklim, cuaca, perubahan harga dan sebagainya. Provinsi Sumatera Utara mulai mengembangkan pertanian organik khususnya untuk tanaman padi untuk mengurangi ketergantungan petani terhadap pestisida dan pupuk kimiawi. Tujuan dari penelitian ini adalah untuk menganalisis factor-faktor produksi yang berpengaruh pada usahatani padi, dan untuk menganalisis tingkat efisiensi penggunaan factor-faktor produksi pada usahatani padi di desa baru kecamatan batang kuis. Metode yang digunakan dalam penelitian in metode deskriptif yaitu pengambilan sampel dan wawancara dengan petani di desa baru Kec.batang kuis. Parameter yang diamati diantaranya analisis factor produksi dan analisis efisiensi penggunaan faktor produksi. Hasil yang didapat dari penelitian bahwanya kebanyakan petani di desa baru merupakan tamatan SMU dan semua factor-faktor produksi berpengaruh sangat nyata terhadap usahatani padi di desa baru. Dan variabel benih,pupuk kimia,pupuk organic,luas lahan dan tenaga kerja sangat signifikan mempengaruhi produksi. Ke depannya diharapkan para petani padi di desa baru dapat meminimalkan penggunaan benih, pupuk kimia dan pestisida sehingga didapatkan produksi padi yang optimal.
\end{abstract}

Kata kunci: Padi, usahatani,efisiensi factor produksi 


\section{A. PENDAHULUAN}

Pertanian merupakan salah satu sektor andalan di provinsi Sumatera Utara, sehingga daerah tersebut sebagai salah satu lumbung beras nasional. Provinsi Sumatera Utara dari tahun ke tahun selalu mengalami surplus padi. Komoditas padi ini diupayakan peningkatan produksi dan produktifitasnya oleh pemerintah Sumatera Utara. Peningkatan yang dicapai selama ini melalui meningkatnya luas tanam dibeberapa daerah serta didukung curah hujan yang cukup. Meningkatnya pemahaman petani dalam upaya meningkatkan produksi seperti pemupukan yang cukup serta lebih selektif dalam memilih bibit, juga menjadi salah satu sebab meningkatnya produksi padi di Sumatera Utara (BPPS, 2015).

Tingkat pendapatan yang diperoleh dari bertanam padi sering kali lebih rendah jika dibandingkan dengan bertanam produk hortikultura atau komoditi pertanian yang lainnya. Dengan demikian, diperlukan upaya agar produksi beras tetap dapat berjalan dan peningkatan pendapatan petani dapat tercipta (Supriadiputra dan Setiawan, 2009).

Usahatani

adalah proses pengorganisasian faktor-faktor produksi yaitu alam, tenaga kerja, modal dan pengelolaan yang diusahakan oleh perorangan ataupun sekumpulan orang untuk menghasilkan output yang dapat memenuhi kebutuhan keluarga ataupun orang lain di samping motif mencari keuntungan (Soekartawi, 1995)

Usahatani padi sawah merupakan kegiatan di bidang pertanian yang mengorganisasikan alam, tenaga kerja, modal dan manajemen, yang ditujukan untuk produksi padi. Keempat unsur, yaitu lahan yang mewakili untuk alam, tenaga kerja yang bertumpu pada anggota keluarga tani, modal yang beraneka ragam jenisnya serta unsur pengelolaan atau manajemen yang peranannya dibawakan oleh seseorang yang disebut petani, saling terkait satu sama lain karena kedudukannya dalam usahatani sama pentingnya sehingga keempat unsur tersebut tidak dapat dipisahkan (Handayani, 2006).

Pada dasarnya usahatani padi memiliki dua faktor yang akan mempengaruhi proses produksi, yaitu faktor internal penggunaan lahan, tenaga kerja dan modal serta faktor-faktor eksternal yang meliputi faktor produksi yang tidak dapat dikontrol oleh petani seperti iklim, cuaca, perubahan harga dan sebagainya.

Menurut Kurniati (1995) dalam Hartono (2000) analisis usahatani bertujuan untuk melihat keberadaan suatu aktivitas usahatani. Usahatani dapat dikatakan berhasil dari segi finansial, apabila usahatani tersebut telah dapat menunjukkan halhal sebagai berikut:
1. Usahatani tersebut menghasilkan penerimaan yang dapat menutupi semua biaya atau pengeluaran.

2. Usahatani tersebut dapat menghasilkan penerimaan tambahan untuk membayar bunga modal yang dipakai, baik modal sendiri maupun modal yang dipinjam.

3. Usahatani tersebut dapat memberikan balas jasa pengelolaan yang wajar kepada petani itu sendiri.

Kesadaran akan pentingnya kesehatan dan kelestarian lingkungan sudah mendorong masyarakat pertanian untuk kembali ke sistem pertanian organic, karena produk yang diharapkan bebas residu pestisida dan pupuk kimia. Selain ramah lingkungan, biaya untuk pertanian organic pun sangat rendah karena pupuk dan pestisida yang digunakan berasal dari alam sekitar petani (AAK, 1990).

Provinsi Sumatera Utara mulai mengembangkan pertanian organik khususnya untuk tanaman padi untuk mengurangi ketergantungan petani terhadap pestisida dan pupuk kimiawi. Dengan pertanian organic diharapkan tanaman padi hasil produksi petani Sumatera Utara bisa memiliki daya saing dan berkualitas, sehingga meningkatkan pendapatan dan perekonomian masyarakat terutama petani di desa baru kecamatan batang kuis.

Dalam pelaksanaan usahatani padi di Desa Baru di upayakan dapat meningkatkan produksi padi dengan meminimumkan biaya produksi.Penggunaan factor produksi yang tepat akan menghasilkan produksi dari usahatani yang maksimal, sehingga akan berpengaruh terhadap pendapatan yang akan diterima petani.

Adapun tujuan dari penelitian ini adalah untuk menganalisis factor-faktor produksi yang berpengaruh pada usahatani padi, dan untuk menganalisis tingkat efisiensi penggunaan factorfaktor produksi pada usahatani padi di desa baru kecamatan batang kuis.

\section{B. METODE}

\section{Tempat dan Waktu Penelitian}

Penelitian ini dilaksanakan di Desa Baru Kecamatan Batang Kuis Kabupaten Deli Serdang. Pemilihan lokasi penelitian dilakukan dengan metode purposive sampling, dengan pertimbangan desa baru merupakan salah satu sentra produksi padi sawah yang mayoritas penduduknya bermata pencaharian sebagai petani padi. Penelitian ini dilaksanakan pada bulan Juni s/d Agustus 2019.

\section{Metode Pengambilan Sampel}

Pengambilan sampel petani dilakukan dengan metode Purposive sampling dengan pertimbangan sampel penelitian bersifat homogen. 
3. Metode analisis data

Analisis Faktor Produksi

Untuk menganalisis pengaruh factor-faktor produksi menggunakan fungsi produksi Cobb Douglas dengan rumus sebagai berikut :

$\mathrm{Y}=\mathrm{a}+\mathrm{b}_{1} \mathrm{X}_{1}+\mathrm{b}_{2} \mathrm{X}_{2}+\mathrm{b}_{2} \mathrm{X}_{3}+\mathrm{b}_{4} \mathrm{X}_{4}+\mathrm{b}_{5} \mathrm{X}_{5}$

Keterangan :

$\mathrm{Y}=$ Jumlah Produksi padi

$\mathrm{X}_{1}=$ Bibit $(\mathrm{kg})$

$\mathrm{X}_{2}=$ Pupuk Kimia $(\mathrm{kg})$

$\mathrm{X}_{3}=$ Pupuk organic $(\mathrm{kg})$

$\mathrm{X}_{4}=$ Luas lahan (rante)

$\mathrm{X}_{5}=$ Tenaga kerja $(\mathrm{HOK})$

$\mathrm{a}, \mathrm{b}=$ besaran yang diduga

Untuk menduga model fungsi produksi padi digunakan persamaan regresi linier berganda dimana model fungsi produksi Cobb Douglas tersebut diubah kedalam bentuk persamaan logaritma natural sehingga menjadi persamaan regresi linier berganda sebagai berikut :

$\mathrm{LnY}=\beta_{0}+\beta_{1} \operatorname{LnX}{ }_{1}+\beta_{2} \operatorname{LnX} X_{2}+\beta_{3} \operatorname{Ln} X_{3}+\beta_{4} \operatorname{LnX} X_{4}+\beta_{5} \operatorname{Ln}$ $\mathrm{X}_{5}$ (Soekartawi, 1995)

Analisis Efisiensi Penggunaan Faktor Produksi Untuk analisis efisiensi penggunaan faktor produksi dapat dilakukan dengan melakukan pengujian efisiensi alokatif atau efisiensi harga. Alokasi penggunaan factor produksi dikatakan efisien apabila nilai produk marginal (NPMxi), sama dengan harga inputnya (Pxi), artinya alokasi sarana produksi telah mencapai titik optimal atau telah efisien. Perbandingan antara nilai produk arginal dengan harga input berada pada titik kombinasi tersebut sama dengan 1. Secara sistematis efisiensi alokati dituliskan sebagai berikut :

NPMXi $=$ PXi, atau NPMXi $=1=\mathrm{Ki}$

Apabila $\mathrm{Ki}=1$, berarti penggunaan input efisien, ki>1 penggunaan input belum efisien dan masih perlu ditambah, sedangkan apabila ki,1 penggunaan input sudah tidak efisien dan perlu dikurangi (Soekartawi, 1994)

\section{PEMBAHASAN dan HASIL}

Dari penelitian yang sudahh dilakukan diperoleh hasil antara lain : tingkat pendidikan petani sampel, Jumlah produksi dan biaya produksi, serta efisiensi penggunaan faktor produksi.

\section{Tingkat Pendidikan Petani Sampel}

Tingkat pendidikan petani sampel terdiri dari SMP,SMA hingga akademik. Secara terperinci dapat dilihat pada tabel 1 dibawah ini
Tabel 1. Karakteristik Petani Sampel Menurut tingkat pendidikan

\begin{tabular}{|l|l|l|l|}
\hline No & $\begin{array}{l}\text { Jlh tanggungan } \\
\text { org tua }\end{array}$ & $\begin{array}{l}\text { Jlh Sampel } \\
\text { (Orang) }\end{array}$ & $\begin{array}{l}\text { Persentase } \\
(\%)\end{array}$ \\
\hline 1 & Tidak Sekolah & 11 & 36.67 \\
\hline 2 & SMP & 5 & 16.67 \\
\hline 3 & SMA & 12 & 40.00 \\
\hline 4 & Akademik & 2 & 6.66 \\
\hline \multicolumn{2}{|c|}{ Jumlah } & 30 & 100 \\
\hline
\end{tabular}

Sumber : Data primer diolah

Berdasarkan tabel 1 diatas, maka dapat diketahui bahwa karakteristik petani sampel menurut tingkat pendidikan terbesar adalah SMA, yaitu sebanyak 12 orang $(40.00 \%)$. Sedangkan yang terkecil adalah akademik yaitu 2 orang (6.66 $\%)$

\section{Pengaruh Faktor-faktor Produksi terhadap Produksi}

Hasil analisis pengaruh faktor-faktor produksi benih, pupuk organic, pupuk kimia, luas lahan dan tenaga kerja terhadap produksi usahatani padi dengan analisis regresi linier berganda melalui program excel sebagai berikut :

Tabel 2. Hasil analisis regresi linier berganda

\begin{tabular}{|c|c|c|c|c|c|}
\hline $\begin{array}{l}\mathrm{N} \\
\mathrm{o}\end{array}$ & Variabel & $\begin{array}{l}\text { Koefi } \\
\text { sien }\end{array}$ & $\begin{array}{l}\text { Std.er } \\
\text { or }\end{array}$ & $\begin{array}{l}\text { Statist } \\
\text { ik }\end{array}$ & $\begin{array}{l}\text { P- } \\
\text { Value }\end{array}$ \\
\hline 1 & Intercept & 1.673 & 0.567 & 2.948 & 0.007 \\
\hline 2 & Benih & 0.170 & 0.079 & 2.146 & 0.042 \\
\hline 3 & $\begin{array}{l}\text { Pupuk } \\
\text { Kimia }\end{array}$ & 0.280 & 0.130 & 2.137 & 0.043 \\
\hline 4 & $\begin{array}{l}\text { Pupuk } \\
\text { organic }\end{array}$ & 0.028 & 0.207 & 0.138 & 0.891 \\
\hline 5 & $\begin{array}{l}\text { Luas } \\
\text { lahan }\end{array}$ & 0.283 & 0.402 & 0.703 & 0.489 \\
\hline 6 & $\begin{array}{l}\text { Tenaga } \\
\text { kerja }\end{array}$ & 0.306 & 0.310 & 0.985 & 0.334 \\
\hline 7 & $\begin{array}{l}\text { R- } \\
\text { Square }\end{array}$ & 0.888 & & & \\
\hline 8 & $\begin{array}{l}\text { Adjust } \\
\text { R- } \\
\text { Square }\end{array}$ & 0.865 & & & \\
\hline 9 & $\begin{array}{l}\text { Fstatisti } \\
\mathrm{k}\end{array}$ & $\begin{array}{l}38.17 \\
2\end{array}$ & & & \\
\hline 10 & $\begin{array}{l}\text { Fsignifi } \\
\text { kan }\end{array}$ & 0.000 & & & \\
\hline
\end{tabular}

Berdasarkan tabel 2 diatas maka dapat dibuat model estimasi sebagai berikut :

$\mathrm{LnY}=1.673+0.170 \operatorname{LnX}_{1}+0.280 \operatorname{LnX}_{2}+0.028 \operatorname{LnX}_{4}$ $+0.306 \mathrm{LnX}_{5}$

Hasil analisa regresi linier berganda berdasarkan tabel 2 menunjukkan bahwa Fhitung sebesar 38.172 dengan signifikan F sebesar 0.000 lebih kecil dari 0.05 (5\%) sehingga menolak H0. Hasil ini menyatakan bahwa secara stimulant 
variable factor-faktor produksi benih (X1), Pupuk Kimia (X2), pupuk organic (X3), luas lahan (X4), tenaga kerja (X5) berpengaruh nyata terhadap produksi (Y). Koefisien adjusted R-square menunjukkan nilai sebesar 0.865 artinya $86.5 \%$ variasi naik turunnya variabel $\mathrm{Y}$ (produksi) dipengaruhi oleh bariasi naik turunnya variabel $\mathrm{X}$ (benih,pupuk kimia,pupuk organic, luas lahan dan tenaga kerja). Sisanya $13.5 \%$ adalah pengaruh variabel lain yang tidak dimasukkan dalam model penelitian ini. Hal ini menggambarkan bahwa variabel benih,pupuk kimia,pupuk organic,luas lahan dan tenaga kerja sangat signifikan mempengaruhi produksi.

\section{Efisiensi penggunaan faktor produksi}

Dari hasil analisis efisiensi penggunaan factor produksi yang menggunakan rasio nilai produk marginal (NPM) dengan harga factor produksi (Px), maka diperoleh hasil pada tabel 3 berikut :

\begin{tabular}{|l|l|l|l|l|l|}
\hline No & $\begin{array}{l}\text { Faktor } \\
\text { prod }\end{array}$ & NPMx & Px & $\begin{array}{l}\text { NPMx/ } \\
\text { Px }\end{array}$ & $\begin{array}{l}\text { E } \\
\text { Fak }\end{array}$ \\
\hline 1 & Benih & 12049,32 & 247.500 & 0.05 & T1 \\
\hline 2 & $\begin{array}{l}\text { Pupuk } \\
\text { Kimia }\end{array}$ & 507276,54 & 1073666.67 & 0.47 & Tid \\
\hline 3 & $\begin{array}{l}\text { Pupuk } \\
\text { organic }\end{array}$ & 21086.32 & 102083.33 & 0.21 & T \\
\hline 4 & $\begin{array}{l}\text { Luas } \\
\text { lahan }\end{array}$ & 10327.99 & 2198907.63 & 0.01 & Tid \\
\hline 5 & $\begin{array}{l}\text { Tenaga } \\
\text { kerja }\end{array}$ & 64592.98 & 1646.920 & 0.04 & T \\
\hline
\end{tabular}

Dalam banyak kenyataan NPMx tidak selalu sama dengan Px (NPMx/Px=1). Dari tabel 3 diatas diketahui bahwa rasio NPMX dengan Px semua hasilnya sama, yaitu lebih kecil dari satu. Apabila $(\mathrm{NPMx} / \mathrm{Px}<1)$ artinya penggunaan input $\mathrm{X}$ tidak efisien dan untuk mencapai tingkst efisien maka input harus dikurangi.

\section{KESIMPULAN}

Dari penelitian ini ditarik kesimpulan sebagai berikut :

1. Secara serentak factor produksi benih,pupuk kimia,pupuk organik, luas lahan dan tenaga kerja secara bersama-sama memberi penjelasan mempunyai pengaruh signifikan terhadap produksi

2. Secara parsial factor produksi benih dan pupuk kimia yang ditandai dengan nilai P-value lebih kecil dari a $0.05 \%$
3. Tingkat pengemballian skala usahatani padi dalam keadaan skala kenaikan hasil yang makin bertambah yaitu input yang ditambhaknan dalam proses produksi menghasilkan skala output yang meningkat, atau dengan kata lain pertambahan jumlah output lebih besar daripada pertambahan jumlah input.

\section{Daftar Pustaka/Referensi}

AAK. 1990. Budidaya Tanaman Padi. Kanisius. Yogyakarta

Balai Penyuluh Pertanian (BPP) Kecamatan Batang Kuis. 2016. Data Luas Lahan Sawah Kecamatan Batang Kuis. Deli Serdang, Sumatera Utara.

Handayani, Dewi Mutia. 2006. Analisis Profitabilitas dan Pendapatan UsahataniPadi Sawah menurut Luas dan Status Kepemilikan Lahan (Studi Kasus Desa Karacak, Kecamatan Leuwiliang, Efisiensid Kapaten Bogor, Jawa Barat). Skripsi. Faktor Program Studi Ekonomi Pertanian dan Tidak Sumberdaya. Fakultas Pertanian, IPB. Tidak Bogor

Fídatono, Rudi. 2000.Analisis Pendapatan Usahatani Markisa dan Faktor-Faktor

Tidak yang Mempengaruhinya (Studi Kasus di Kecamatan Tinggimoncong, Kabupaten

Tidak Gowa, Privinsi Sulawesi Selatan). Skripsi. Departemen Ilmu- Ilmu Sosial Ekonomi Pertanian. Fakultas Pertanian. IPB. Bogor

Machfudz,M., 2007. Dasar-dasar Ekonomi Mikro.Prestasi Pustaka, Jakarta.

Soekartawi, 1994. Teori Ekonomi Produksi dengan pokok bahasan analisis Fungsi produksi Cobb Douglas. Raja grafindo Persada, Jakarta.

Soekartawi. 1995. Analisis Usahatani. UI-Press. Jakarta

Supriadiputra, Sudirman dan Ade Iwan Setiawan. 2009. Mina padi Budidaya Ikan Bersama Padi. Penebar Swadaya. Jakarta

Wardhani,P.K, 2012. Analisis Efisiensi Produksi dan Pendapatan pada usaha peternakan ayam ras pedaging di kecamatan Limbangan Kabupaten Kendal. 